\title{
An Accessory Abductor Digiti Minimi as Possible Risk Factor of the Median and Ulnar Nerves Compression
}

\author{
Músculo Abductor Digiti Minimi Accesorio como Posible Factor \\ de Riesgo de la Compresión de los Nervios Mediano y Ulnar
}

Javier Catón; Elena Martínez-Sanz ${ }^{1}$; Julio Morán-Morán²; Pedro López-Fernández ${ }^{3,4}$ \& Jorge Murillo-González ${ }^{1}$

CATÓN, J.; MARTÍNEZ-SANZ, E.; MORÁN-MORÁN, J.; LÓPEZ-FERNÁNDEZ, P. \& MURILLO-GONZÁLEZ, J. Músculo abductor digiti minimi accessorius como posible factor de riesgo de la compresión de los nervios mediano y ulnar. Int. J. Morphol., $38(6): 1555-1559,2020$.

SUMMARY: During routine dissection of a left upper limb of a 68-year-old male human cadaver, an unusual muscle was observed originating from the radius and flexor retinaculum, and continued in the hypothenar region with the muscle belly of the abductor digiti minimi. We checked that it was an accessory abductor digiti minimi (ADM). Its muscular belly was in close relation to the median and ulnar nerves. We review the literature regarding such muscle variations and discuss the potential for compression of the median and ulnar nerves. Although the accessory ADM is usually asymptomatic and only rarely results in nerve compression, it should be taken into account by surgeons when establishing a differential diagnosis in the compression neuropathies of the median and ulnar nerves. An ultrasound scanning can help establish the differential diagnosis.

KEY WORDS: Accessory abductor digiti minimi; Entrapment; Median nerve; Ulnar nerve.

\section{INTRODUCTION}

Anatomical variations of hypothenar muscles are well documented (González \& Netscher, 2016). The accessory abductor digiti minimi (ADM) is considered the most variable of all the hypothenar muscles (Harvie et al., 2004). Variations related to the flexor digiti minimi brevis muscle seem to occur less frequently and the variations related to the opponens digiti minimi are rare (Claassen et al., 2013).

The reported variations of the ADM are absence, presence of one to three muscle bellies, variations of their origin (fascia of the forearm, palmaris longus tendon, fascia of the flexor carpi radialis, intermuscular fascia, flexor carpi ulnaris, pronator quadratus, flexor retinaculum, ulna and the anterior face of the distal epiphysis of the radius), fusion with the flexor digiti minimi brevis and presence of "deep abductor-flexor" (Macalister, 1875; Le Double, 1897; Jeffery, 1971; Simodynes \& Cochran 2nd, 1981; Soldado-
Carrera et al., 2000; Georgiev et al., 2007; González \& Netscher).

The existence of accessory hypothenar muscles is usually asymptomatic and seldom is followed by nerve compression (Ballesteros \& Ramirez, 2007). These accessory muscles can be associated with compression of the ulnar nerve but usually not with compression of the median nerve (De Smet, 2002).

At the wrist, compression neuropathy of the median and ulnar nerves associated with the same muscle variant never has been documented (Zeiss \& Jakab, 1995).

In this study, we present an accessory ADM which muscular belly was in close relation to the median and ulnar nerves, being able to constitute a risk factor in their compression.

\footnotetext{
${ }^{1}$ Department of Anatomy and Embryology, Faculty of Medicine, Complutense University of Madrid, Madrid, Spain

${ }^{2}$ Service of Orthopedic Surgery and Traumatology, University General Hospital "Gregorio Marañón", Madrid, Spain

${ }^{3}$ Division of Human Anatomy and Embryology, Department of Basic Health Sciences, Rey Juan Carlos University, Madrid, Spain.

${ }^{4}$ Department of Surgery, University Hospital Rey Juan Carlos, Madrid, Spain.

Funding Sources. This study was funded by a grant from the Complutense University of Madrid to the Complutense Research Group 920202 (grant number GR29/20).
} 


\section{CASE REPORT}

During routine anatomical dissection of the left upper limb of a 71-year-old human male cadaver, an accessory ADM was observed. The complete dissection is shown in Figures 1 to 3. The specimen was fixed in $10 \%$ formaldehyde solution. The anomalous muscle was only present on the left side. The accessory ADM originated at two sites at the radial side: 1) from the anterior margin of the radial styloid process below the pronator quadratus; 2 ) from the flexor retinaculum, next to the origin of the thenar muscles. It coursed obliquely and distally superficial to the flexor pollicis longus, median nerve (before the nerve passed through the carpal tunnel), flexor digitorum superficialis, ulnar nerve, its terminal branches (superficial and deep) and the deep palmar branch of the ulnar artery. The muscle passed underneath the radial artery, flexor carpi radialis, ulnar artery and palmaris brevis. Palmaris longus muscle was absent in this limb. The ulnar artery adopted a superficial course above the accessory
ADM and deep to the palmar brevis muscle, whereas the ulnar nerve and its terminal branches were found to lie beneath the accessory ADM. This anomalous muscle was continuous in the hypothenar region, with the abductor digiti minimi that is inserted into the ulnar aspect of the base of the proximal phalanx and into the ulnar lateral band of the dorsal aponeurosis. The total length of the accessory ADM was $73 \mathrm{~mm}$. At the level of the median nerve, the muscle had a width of $25 \mathrm{~mm}$ and a thickness of $1.7 \mathrm{~mm}$. At the level of the ulnar nerve, the muscle had a width of $15 \mathrm{~mm}$ and a thickness of $2.3 \mathrm{~mm}$.

Vascularization seems to arise from palmar carpal branch of the radial artery that was seen to penetrate near the origin of the accessory ADM. Regarding its innervation, a common trunk has been observed arising from the deep branch of the ulnar nerve destined to innervate the ADM and the accessory ADM, just distal to the pisiform.
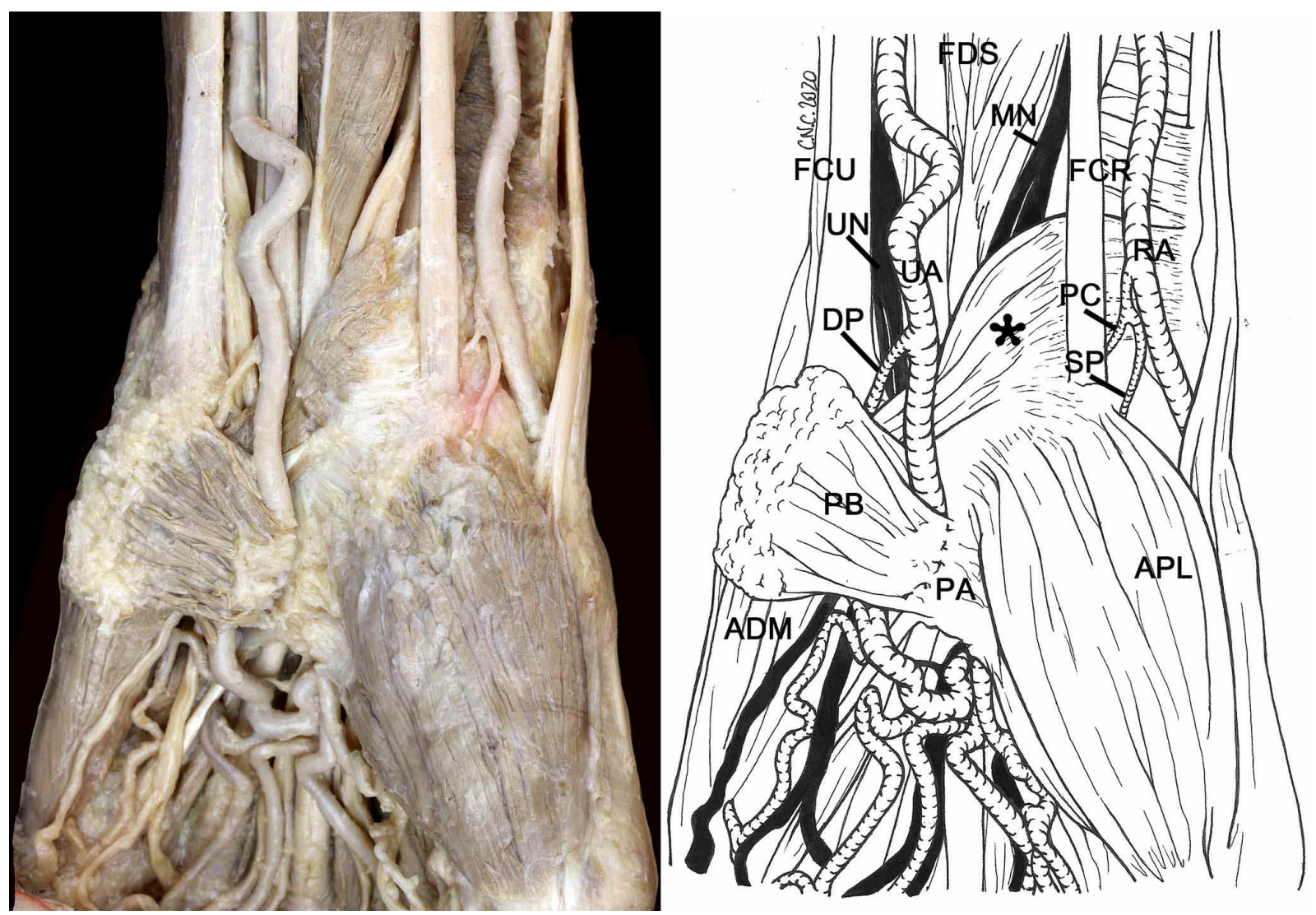

Fig. 1. Ventral view of the lower third of the forearm and hand. Asterisk - accessory ADM; ADM - abductor digiti minimi; APL - abductor pollicis longus; DP - deep palmar branch; FCR - flexor carpi radialis; FCU - flexor carpi ulnaris; FDS - flexor digitorum superficialis; MN - median nerve; PA - palmar aponeurosis; PB - palmaris brevis; PC - palmar carpal branch; RA radial artery; $\mathrm{SP}$ - superficial palmar branch; UA - ulnar artery; UN - ulnar nerve. 

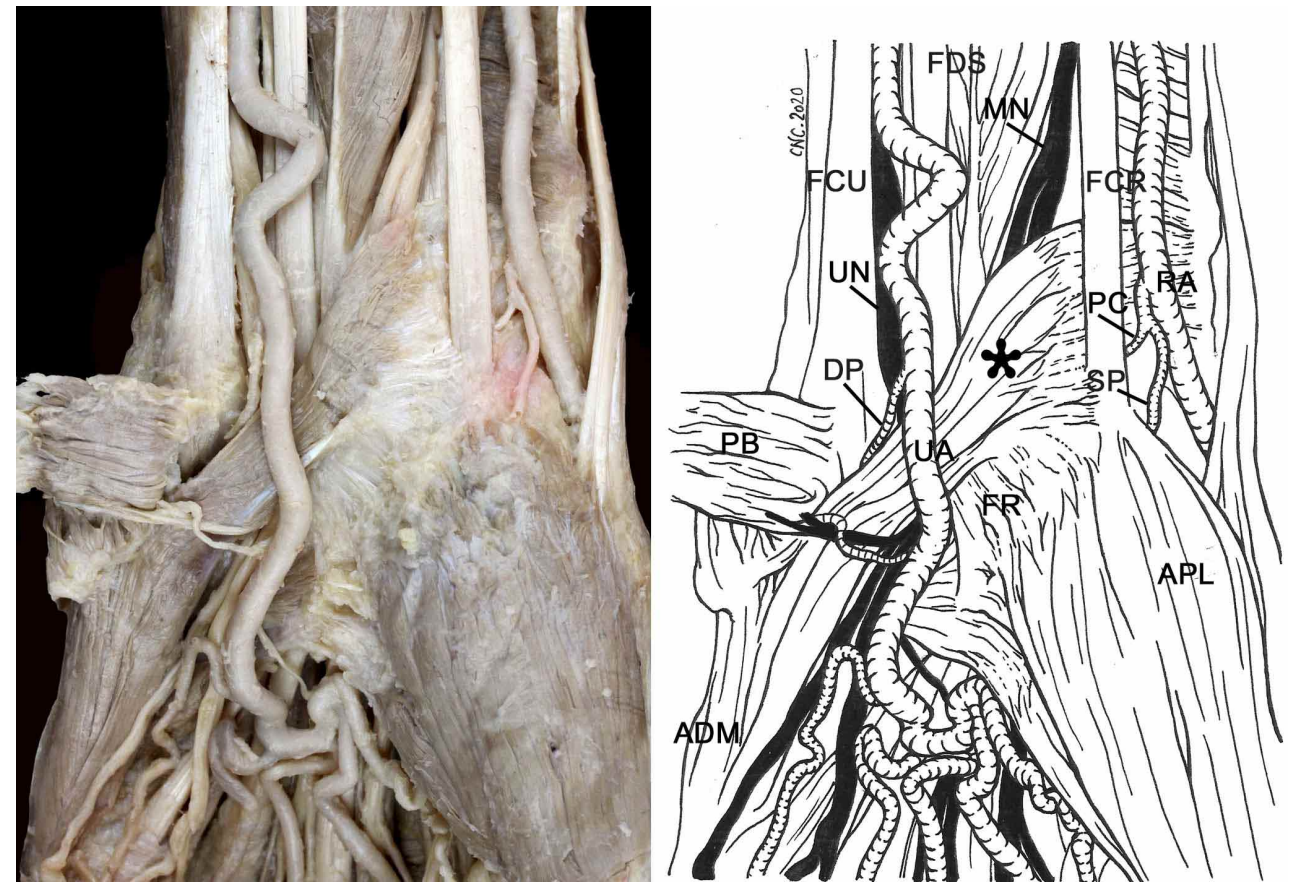

Fig. 2. Same as Figure 1 after resection of the palmaris brevis (PB). Asterisk - accessory ADM; ADM - abductor digiti minimi; APL - abductor pollicis longus; DP - deep palmar branch; FCR - flexor carpi radialis; FCU - flexor carpi ulnaris; FDS - flexor digitorum superficialis; FR - flexor retinaculum; MN - median nerve; PC - palmar carpal branch;RA - radial artery; SP - superficial palmar branch; UA ulnar artery; UN - ulnar nerve.
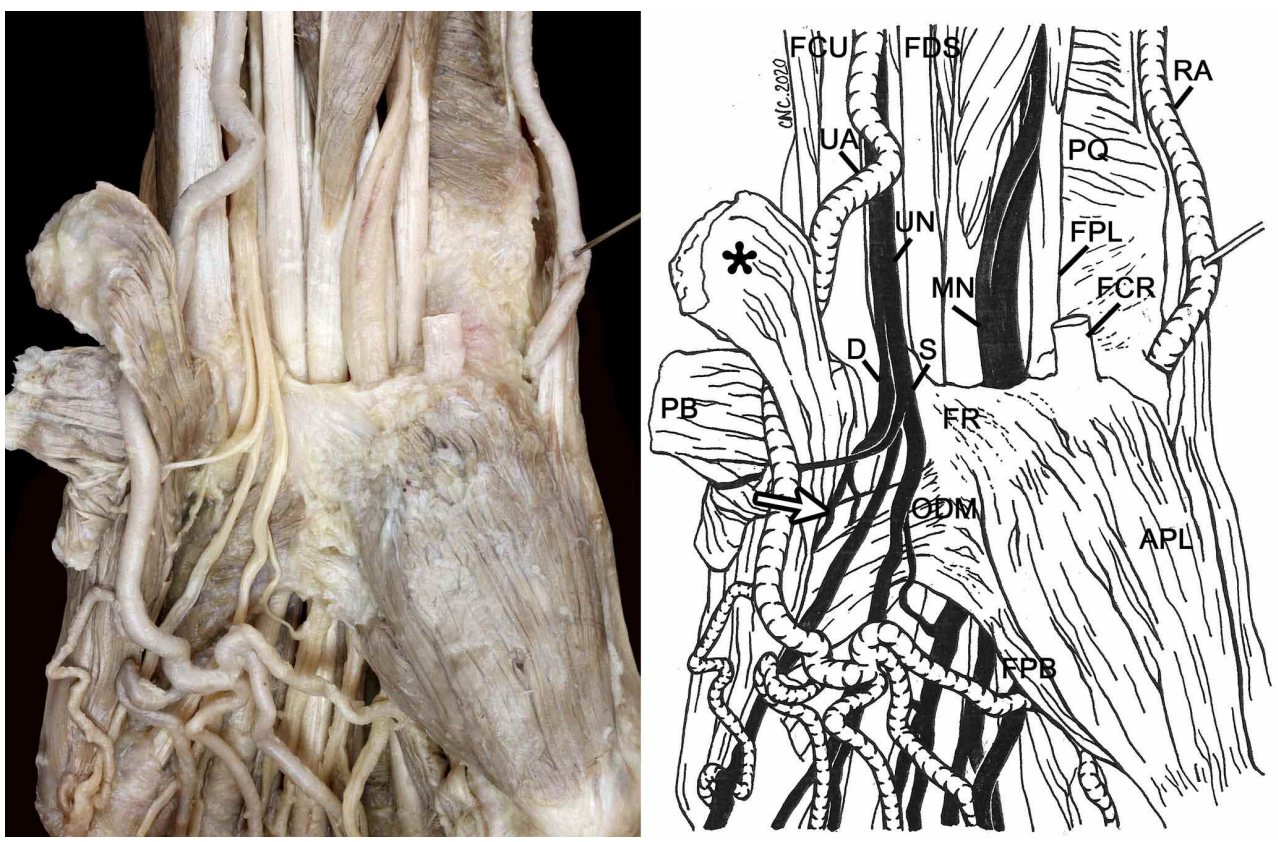

Fig. 3. Same as Figure 2 after resection of the flexor carpi radialis (FCR). The accessory ADM (asterisk) have been rejected in the medial sense. The radial (RA) and ulnar (UA) arteries have been rejected in the lateral and medial senses respectively. Arrow - innervation of the accessory ADM; APL - abductor pollicis longus; D - deep branch; FCU - flexor carpi ulnaris; FDS - flexor digitorum superficialis; FPB - flexor pollicis brevis; FPL - flexor pollicis longus; FR - flexor retinaculum; MN - median nerve; ODM - opponens digiti minimi; PB - palmaris brevis; PQ - pronator quadratus; RA - radial artery; S superficial branch; UA - ulnar artery; UN - ulnar nerve. 
CATÓN, J.; MARTÍNEZ-SANZ, E.; MORÁN-MORÁN, J.; LÓPEZ-FERNÁNDEZ, P. \& MURILLO-GONZÁLEZ, J. Músculo abductor digiti minimi accessorius como posible factor de riesgo de la compresión de los nervios mediano y ulnar. Int. J. Morphol., 38(6):1555-1559, 2020.

\section{DISCUSSION}

With respect to the possible ontogenic interpretation of this anomalous muscle, it should first be noted that original undifferentiated mesenchyme of the hand divides at an early stage into 2 layers, superficial and deep. The superficial layer differentiates earlier, giving rise to three blastemas, radial, middle and ulnar, that give rise to the abductor pollicis brevis, flexor digitorum superficialis (FDS) and ADM muscles respectively. The remainder of the hypothenar muscles are derived from the deep layer and develop at a later stage. Thus, the primordium of FDS has its origin in the carpal region and then migrates towards the forearm to its definitive position, while the ADM and abductor pollicis brevis muscles take origin where their blastema originated (Cihák, 1972).

In relation to the antebrachial origin of the supernumerary fascicles and their ulnar innervation, Soldado et al. ascribe it to an undifferentiated group of mesenchymal cells (due probably to a failure in their usual programmed cell death during the splitting process). These cells come from the superficial layer between the FDS and ADM blastemas. They suggest that the common carpal origin of the ADM and FDS muscles and the antebrachial migration of the latter may be supported in this way.

According to Soldado et al., this explanation diverges from previous ones (Sälgeback, 1977; Cantero, 1981; Sañudo et al., 1993), which explained the presence of this anomaly by a proximal abnormal migration of the blastema of the hypothenar muscles.

In three different cadaveric, MR and ultrasound studies, the prevalence of the accessory ADM has been reported 22.4, 25 and $35 \%$, respectively; occurring bilateral between 46.2 to $67 \%$ of cases (Dodds 3rd et al., 1990; Zeiss et al., 1992; Harvie et al., 2004).

In clinical practice, variant muscular structures in the anterior wrist region could be incidentally found during surgical procedures without provoking clinical symptoms or may simulate a soft-tissue tumor (Simodynes \& Cochran 2nd). However, some musculotendinous anomalies may cause median or ulnar nerves compression with slow progressive symptoms or rarely acute nerve compression (Georgiev \& Jelev, 2009). The ADM and palmaris longus are the most frequently reported anomalous muscles that can be associated with compression of the ulnar nerve (Santoro et al., 2000), and the FDS, lumbricals and palmaris longus with compression of the median nerve (Zeiss \& Jakab).

Both MRI and ultrasound can accurately determine the presence of an anomalous muscle, its size and anatomical relations. Compared to MRI, ultrasound is dynamic imaging, rapid, with higher spatial resolution, lower cost and higher acceptability by the patient (Harvie et al., 2003).

The existence of an accessory ADM is relatively common, usually asymptomatic and seldom is followed by nerve compression (Ballesteros \& Ramirez). They can be associated with compression of the ulnar nerve, but usually not with compression of the median nerve (Jeffery ; De Smet; Al-Qattan, 2004)

We have only found two cases reported in the literature of an accessory ADM covering the median nerve (Jackson \& Harkins, 1972; Sañudo et al.).

When the anomalous muscles produce clinical symptoms, they appear to be related to their anatomical location and the size (Jeffery; Ballesteros \& Ramirez). One can suspect the presence of such anomalous muscle when the compression syndrome concerns a patient who is not within the "usual" age group with symptoms initiated or aggravated by physical exercise. Thus, in younger patients and manual workers, the possibility of nerve compression by aberrant muscles should be considered (De Smet). Harvie et al. (2004), in an ultrasound study performed in 116 wrists of asymptomatic volunteers, anomalous muscles were identified in $35 \%$ of wrists. They propose than when an anomalous muscle is identified alternative causes of ulnar nerve compression should be sought if the size of this muscle is not significantly above the population mean thickness of $1.7 \mathrm{~mm}$. In the present case, when considering the morphometric parameters of the accessory ADM (length, width and thickness), the shrinkage experienced by formaldehyde fixation must be taken into account. The accessory ADM had a thickness of $1.7 \mathrm{~mm}$ at the level of the median nerve and $2.3 \mathrm{~mm}$ at the level of the ulnar nerve.

At the wrist, compression neuropathy of the median and ulnar nerves associated with the same muscle variant has never been documented (Zeiss \& Jakab).

In our case, it is not known whether there was symptomatic compression of the median and / or ulnar nerves because of the postmortem nature of the study, but no gross atrophy of the muscles of the hand innervated by the ulnar and median nerves was observed compared with the opposite hand. However, it is possible to think that the case of reported accessory ADM, with the dimensions and relationships with both the ulnar and median nerves, could cause a compressive neuropathy. 
CONCLUSION. Although the accessory ADM is usually asymptomatic and only rarely results in nerve compression, knowledge of their location and frequency can help avoid surgeon confusion during clinical examination. In cases of suspected ulnar and / or median nerves compression, an ultrasound scanning can help establish the differential diagnosis.

Funding Sources. This study was funded by a grant from the Complutense University of Madrid to the Complutense Research Group 920202 (grant number GR29/20).

ACKNOWLEDGEMENTS. The authors thank Ms. Cristina Navarro for drawing the illustrations. We thank to all those people who anonymously, altruistically and in solidarity donate their body to science. Without his valuable gesture, it would not have been possible to carry out this work.

CATÓN, J.; MARTÍNEZ-SANZ, E.; MORÁN-MORÁN, J.; LÓPEZ-FERNÁNDEZ, P. \& MURILLO-GONZÁLEZ, J. Músculo abductor digiti minimi accesorio como posible factor de riesgo de la compresión de los nervios mediano y ulnar. Int. J. Morphol., 38(6):1555$15559,2020$.

RESUMEN: Durante la disección de rutina de un miembro superior izquierdo de un cadáver humano masculino de 68 años, se observó un músculo inusual que se originaba en el radio y el retináculo flexor del carpo, y continuuaba en la región hipotenar con el vientre muscular del abductor digiti minimi manus. Verificamos que se trataba del músculo abductor digiti minimi accessorius (ADMA). Su vientre muscular se encontraba en estrecha relación con los nervios mediano y ulnar. Revisamos la literatura sobre variaciones musculares y discutimos la potencial compresión de los nervios mediano y ulnar. Aunque el ADMA suele ser asintomático y rara vez produce compresión nerviosa, los cirujanos deben tenerlo en cuenta al establecer un diagnóstico diferencial en las neuropatías de compresión de los nervios mediano y ulnar. Una ecografía puede ayudar a establecer el diagnóstico diferencial.

PALABRAS CLAVE: Músculo abductor digiti minimi accessorius; Atrapamiento; Nervio mediano; Nervio ulnar.

\section{REFERENCES}

Al-Qattan, M. M. Ulnar nerve compression at the wrist by the accessory abductor digiti minimi muscle: wrist trauma as a precipitating factor. Hand Surg., 9(1):79-82, 2004

Ballesteros, L. E. \& Ramirez, L. M. Possible implications of an accessory abductor digiti minimi muscle: a case report. J. Brachial Plex. Peripher. Nerve Inj., 2:22, 2007.

Cantero, J. Contribution a l'Etude des Anomalies Musculaires de la Main et de l'Avant-Bras. Thesis. Lausanne, University of Lausanne, 1981. pp.57-70.

Cihák, R. Ontogenesis of the skeleton and intrinsic muscles of the human hand and foot. Ergeb. Anat. Entwicklungsgesch., 46(1):5-194, 1972.

Claassen, H.; Schmitt, O.; Schulze, M. \& Wree, A. Variation in the hypothenar muscles and its impact on ulnar tunnel syndrome. Surg. Radiol. Anat., 35(10):893-9, 2013.
De Smet, L. Median and ulnar nerve compression at the wrist caused by anomalous muscles. Acta Orthop. Belg., 68(5):431-8, 2002.

Dodds 3rd, G. A.; Hale, D. \& Jackson, W. T. Incidence of anatomic variants in Guyon's canal. J. Hand Surg. Am., 15(2):352-5, 1990.

Georgiev, G. P. \& Jelev, L. Unusual coexistence of a variant abductor digiti minimi and reversed palmaris longus and their possible relation to median and ulnar nerves entrapment at the wrist. Rom. J. Morphol. Embryol., 50(4):725-7, 2009.

Georgiev, G. P.; Jelev, L. \& Surchev, L. Undescribed variant muscle--"deep abductor-flexor" of the little finger, in relation to ulnar nerve compression at the wrist. Ann. Anat., 189(3):276-82, 2007.

González, M. A. \& Netscher, D. T. Hand Intrinsic Muscles. In: Tubbs, R. S.; Shoja, M. M. \& Loukas, M. (Eds.). Bergman's Comprehensive Encyclopedia of Human Anatomic Variation. Hoboken, John Wiley \& Sons, 2016. pp.315-34.

Harvie, P.; Patel, N. \& Ostlere, S. J. Prevalence and epidemiological variation of anomalous muscles at Guyon's canal. J. Hand Surg. Br., 29(1):26-9, 2004.

Harvie, P.; Patel, N. \& Ostlere, S. J. Ulnar nerve compression at Guyon's canal by an anomalous abductor digiti minimi muscle: the role of ultrasound in clinical diagnosis. Hand Surg., 8(2):271-5, 2003.

Jackson, D. W. \& Harkins, P. D. An aberrant muscle belly of the abductor digiti quinti associated with median nerve paresthesias. Bull. Hosp. Joint Dis., 33(2):111-5, 1972.

Jeffery, A. K. Compression of the deep palmar branch of the ulnar nerve by an anomalous muscle. Case report and review. J. Bone Joint Surg. Br., 53(4):718-23, 1971.

Le Double, A. F. Traité des Variations du Système Musculaire de l'Homme et de Leur Signification au Point de Vue de l'Anthropologie Zoologique. Tome II. Paris, Reinwald Schleicher Frères Editeurs, 1897. pp.153-217.

Macalister, A. Additional observations on muscular anomalies in human anatomy (third series), with a catalogue of the principal muscular variations hitherto published. Trans. R. Irish Acad., 25:1-134, 1875.

Sälgeback, S. Ulnar tunnel syndrome caused by anomalous muscles. Case report. Scand. J. Plast. Reconstr. Surg., 11(3):255-8, 1977.

Santoro, T. D.; Matloub, H. S. \& Gosain, A. K. Ulnar nerve compression by an anomalous muscle following carpal tunnel release: A case report. J. Hand Surg. Am., 25(4):740-4, 2000.

Sañudo, J. R.; Mirapeix, R. M. \& Ferreira, B. A rare anomaly of abductor digiti minimi. J. Anat., 182(Pt. 3):439-42, 1993.

Simodynes, E. E. \& Cochran 2nd, R. M. Anomalous muscles in the hand and wrist--Report of three cases. J. Hand Surg. Am., 6(6):553-4, 1981.

Soldado-Carrera, F.; Vilar-Coromina, N. \& Rodríguez-Baeza, A. An accessory belly of the abductor digiti minimi muscle: a case report and embryologic aspects. Surg. Radiol. Anat., 22(1):51-4, 2000.

Zeiss, J. \& Jakab, E. MR demonstration of an anomalous muscle in a patient with coexistent carpal and ulnar tunnel syndrome. Case report and literature summary. Clin. Imaging, 19(2):102-5, 1995.

Zeiss, J.; Jakab, E.; Khimji, T. \& Imbriglia, J. The ulnar tunnel at the wrist (Guyon's canal): normal mr anatomy and variants. AJR Am. J. Roentgenol., 158(5):1081-95, 1992.

\section{Corresponding author:}

Jorge Murillo-González

Department of Anatomy and Embryology

Faculty of Medicine, Complutense

University of Madrid

28040 Madrid

SPAIN

Email: jmurillo@ucm.es

Received: 11-05-2020

Accepted: 14-06-2020

ORCID ID: 0000-0002-3455-2378 